Mistreatment in Organizations: Toward a Perpetrator-Focused Research Agenda

\author{
Reeshad S. Dalal, Ph.D. \\ Department of Psychology \\ George Mason University \\ 4400 University Drive, MSN 3F5 \\ Fairfax, VA 22030, U.S.A. \\ Telephone: 703-993-9487 \\ Email: rdalal@gmu.edu \\ Zitong Sheng, M.A. \\ School of Business \\ Virginia Commonwealth University \\ Snead Hall, Room B3142 \\ 301 W. Main Street, P.O. Box 844000 \\ Richmond, VA 23284-4000, U.S.A. \\ Telephone: 703-470-1992 \\ Email: shengz@vcu.edu
}




\section{Mistreatment in Organizations: Toward a Perpetrator-Focused Research Agenda}

Cortina et al. (2017) have cogently suggested that workplace mistreatment should be viewed through a "lens" that squarely implicates the perpetrator (i.e., the perpetrator predation framework) rather than through a lens that at least partially absolves the perpetrator while blaming the victim for inviting, or not actively resisting, the mistreatment (i.e., the victim precipitation framework). We agree that the perpetrator predation framework provides a better basis for policy, practice, and law. Furthermore, however, the perpetrator predation framework provides a better basis for science. Whereas Cortina et al. allude briefly to the scientific benefits of a perpetrator-focused framework, the current commentary fleshes out these benefits and outlines an agenda for future perpetrator-focused research on workplace mistreatment.

To an extent, industrial and organizational (I/O) psychology does have a history of emphasizing the role of the perpetrator. Notably, the research literature on counterproductive work behavior has typically focused on the perpetrator (e.g., Berry et al., 2007). Workplace mistreatment is the interpersonally-directed form of counterproductive work behavior. Yet, the perpetrator perspective adhered to in this literature is rather limited, focusing on perpetrators' dispositional tendencies (e.g., personality traits like conscientiousness), appraisals of the job situation (e.g., job satisfaction), and, more recently, momentary reactions to discrete workplace events (e.g., state negative affect; see Dalal, 2005; Dalal, Lam, Weiss, Welch, \& Hulin, 2009). Workplace mistreatment, however, is an interpersonal process--and therefore the dearth of dyadic perpetrator-victim research, let alone conceptual models, in I/O psychology is striking (Venkataramani \& Dalal, 2007).

What would such conceptual models look like? As Cortina et al. (2017) note, a perpetrator-focused framework does not hold victim characteristics or behavior irrelevant to 
victim mistreatment. Rather, such a framework holds that the proximal antecedents to victim mistreatment involve perpetrator-related constructs: for instance, perpetrators' appraisals of victims' characteristics and behavior. This simple insight opens up many fertile areas for conceptual models that include additional perpetrator-focused constructs and that generate testable propositions.

In the remainder of this commentary, we discuss several conceptual models aimed at igniting perpetrator-focused research on interpersonal mistreatment.

\section{An “Antecedents to Perpetrator Appraisals" Model}

According to this model, perpetrators' appraisals of victims' characteristics/behavior are tainted by situational factors and perpetrator dispositional factors. Consider, for example, sexual harassment. A relevant situational factor influencing perpetrators' appraisals of victims might include the extent to which the organizational climate is tolerant of sexual harassment

(Fitzgerald, Drasgow, Hulin, Gelfand, \& Magley, 1997), and a relevant perpetrator dispositional factor might include individual differences in the likelihood to sexually harass (Pryor, 1987).

At least two implications arise from this model:

1. Situational conditions may facilitate and in some cases even actively encourage victimization. This does not equate to victims precipitating their own victimization. For example, women who choose to enter currently and historically "male" jobs in organizations that remain tolerant of sexual harassment cannot be considered to have "brought it on themselves" (or, worse, been "asking for it").

2. Perpetrator dispositions can be conducive to their beliefs that victims "deserve" victimization. Such dispositions serve to implicate, not absolve, perpetrators. 
Moreover, such a model suggests that future research could examine the situational and perpetrator dispositional factors that influence perpetrators' appraisals of victims' characteristics/behavior--both the factors common to various forms of mistreatment and the factors unique to each form of mistreatment.

\section{A "Perpetrator Motives" Model}

Counterproductive work behavior need not involve an intent to harm the organization. Rather, such behavior need merely be intentional (as opposed to accidental) and have the effect of harming the organization's legitimate interests (Sackett, 2002). This definition permits a multitude of motives (Winter, John, Stewart, Klohnen, \& Duncan, 1998) to be associated with counterproductive work behavior--and with interpersonal mistreatment more specifically. Unfortunately, research on motives for interpersonal mistreatment remains in its infancy. A perpetrator motives model would, unsurprisingly, add perpetrator motives to the basic perpetrator-focused framework outlined above. Specifically, according to such a model: Perpetrator appraisals of victim characteristics/behavior $\rightarrow$ Perpetrator motives for mistreatment of victims $\rightarrow$ Perpetrator mistreatment of victims. A preliminary (noncomprehensive) list of motives for interpersonal mistreatment might include the following:

- Harming the victim

- Harming the organization (indirectly, via the victim, who is an employee of the organization)

- Providing a warning to the victim and/or bystanders regarding the perpetrator's power to inflict harm

- Relieving frustration engendered by a powerful third party by displacing aggression toward the victim (who is less powerful) 
- Relieving frustration engendered by an inanimate/unavailable source (e.g., a broken thermostat in the office) by displacing aggression toward the victim (who is alive/available)

- Discriminating against a member of a legally protected group (e.g., a racial minority group), albeit in a more "modern"--that is, ostensibly demographically neutral-manner (see Cortina et al., 2017)

- Addressing perceived underpayment inequity vis-a-vis the victim

- Relieving frustration engendered by the victim's characteristics or behavior

At least two implications arise from this preliminary list of motives:

1. The victim precipitation framework, even if taken at face value, is consistent only with the last (and, in a generous reading, the second last) of these motives. This suggests the scientific inadequacy of the victim precipitation framework in "explaining" interpersonal mistreatment.

2. In many cases, perpetrators may respond in a socially desirable manner when asked to indicate their motives. Perpetrators' stated motives, in other words, frequently may not match their actual motives. One way to respond in a socially desirable manner is for perpetrators to (falsely) invoke a motive consistent with the victim precipitation framework. This suggests that although the victim precipitation framework may appear to be somewhat useful on the basis of perpetrators' stated motives, it is actually likely to be considerably less useful. It also suggests that organizations should actively strive to reduce the social acceptability of victim precipitation motives in most if not all cases. 
Moreover, a focus on perpetrator motives suggests several avenues for future research. First, future research could develop and validate a comprehensive taxonomy of perpetrator motives for victim mistreatment. Second, future research could examine how frequently these motives are invoked in naturalistic (vs. laboratory) settings. Third, future research could examine how personality traits interact with motives (Winter et al., 1998) in determining victim mistreatment. Fourth, future research could examine how both personality traits (e.g., selfmonitoring) and situational factors (e.g., organizational climate, situational strength) determine the extent to which perpetrators' stated motives match their actual motives. Fifth, future research could examine the effectiveness of various methodological approaches (e.g., policy capturing designs; Tomassetti, Dalal, \& Kaplan, 2016) in reducing socially desirable responding in the context of motives.

\section{A “Perpetrator Regulation Strategies" Model}

According to this conceptual model, the relationship between perpetrator appraisal of victim characteristics/behavior, on the one hand, and perpetrator mistreatment of the victim, on the other hand, is moderated (specifically, weakened) by the use of one or more perpetrator selfregulation strategies (Gross \& John, 2003). One frequently studied strategy involves a cognitive reappraisal of the situation, so as to reduce its negative emotional content. For instance, rather than viewing the victim as being obstructive, the perpetrator may view the victim as trying to save the perpetrator from making an embarrassing mistake. A second frequently studied strategy involves suppressing one's negative-emotion-consistent behavior. For instance, the perpetrator may feel great anger toward the victim but may successfully suppress the urge to display and/or act on that anger. Additionally, there appear to exist individual differences in the extent to which perpetrators enact strategies such as reappraisal and suppression (Gross \& John, 2003): some 
perpetrators, perhaps those scoring low on emotional intelligence, employ neither of these strategies on a habitual basis.

Of course both reappraisal and suppression are emotion-focused self-regulation strategies. Perpetrators could also engage in problem-focused self-regulation strategies. For example, rather than mistreating victims, perpetrators could seek "win-win" solutions or compromises. Alternately, perpetrators could ask third parties to mediate or adjudicate disputes. Mistreating victims is rarely the only available solution.

Finally, even in the rare event that negative behavior directed at the victim truly is the only possible option, such behavior could be modulated in both form and severity. For example, withholding discretionary help (i.e., organizational citizenship behavior) is less egregious than enacting harm (i.e., counterproductive work behavior). As another example, a "forgiving" variant of the Tit-for-Tat strategy (Axelrod, 2006) serves to encourage cooperation and forgive occasional bad behavior (thereby reducing the likelihood of an escalation of bad behavior) while nonetheless communicating an unwillingness to be taken advantage of.

A focus on perpetrator self-regulation strategies, therefore, once again brings the inadequacies of the victim precipitation framework into relief. Mistreatment is the result not of victim "precipitation" but rather of perpetrator unwillingness or inability to self-regulate.

Moreover, a focus on perpetrator self-regulation strategies suggests several avenues for future research. First, because existing research has focused on only a subset of self-regulation strategies (Gross \& John, 2003), future research could focus on developing a taxonomy of strategies that vary not only in their focus (e.g., emotions vs. behavior) and the stage of the process at which they operate (e.g., antecedent-focused strategies like reappraisal vs. responsefocused strategies like suppression) but also in their form (e.g., withholding citizenship behavior 
vs. enacting counterproductive behavior) and their severity (e.g., escalatory vs. de-escalatory). Second, future research could examine how frequently these strategies are used in naturalistic settings. Third, future research could examine the conditions under which each self-regulation strategy is effective. Fourth, future research could continue to design, test, and systematically compare (in terms of cost-effectiveness) interventions aimed at developing effective selfregulation strategies.

\section{Conclusion}

The victim precipitation framework falls short of being a scientific theory in the following ways:

1. It ignores the fact that perpetrator appraisals of victim characteristics and behavior are likely to be tainted by the situation and by the perpetrator's personality.

2. It ignores the fact that perpetrators are likely to have multiple motives for mistreating victims, almost all of which cannot be "explained" by the victim precipitation framework.

3. It ignores the fact that perpetrators may conceal their true motives and may invoke victim precipitation so as to portray themselves in a more socially desirable manner.

4. It ignores the fact that victim mistreatment is likely to be the result of an unwillingness or inability to self-regulate on the part of perpetrators. Perpetrators almost always have, at their disposal, options other than mistreatment.

For these reasons, we echo Cortina et al.'s (2017) contentions. I/O researchers should seek to understand rather than gloss over the role of perpetrators, and I/O practitioners should seek to implicate rather than absolve perpetrators. 


\section{References}

Axelrod, R. M. (2006). The evolution of cooperation (revised edn.). Cambridge, MA: Basic Books.

Berry, C. M., Ones, D. S., \& Sackett, P. R. (2007). Interpersonal deviance, organizational deviance, and their common correlates: A review and meta-analysis. Journal of Applied Psychology, 92, 410-424.

Cortina, L. M., Caridad Rabelo, V., \& Holland, K. J. (2017). Beyond blaming the victim: Toward a more progressive understanding of workplace mistreatment. In press, Industrial and Organizational Psychology: Perspectives on Science and Practice.

Dalal, R. S. (2005). A meta-analysis of the relationship between organizational citizenship behavior and counterproductive work behavior. Journal of Applied Psychology, 90, 12411255.

Dalal, R. S., Lam, H., Weiss, H. M., Welch, E., \& Hulin, C. L. (2009). A dynamic approach to organizational citizenship behavior and counterproductive work behavior: Behavioral cooccurrence and switching, and dynamic relationships with mood and overall job performance. Academy of Management Journal, 52, 1051-1066.

Fitzgerald, L. F., Drasgow, F., Hulin, C. L., Gelfand, M. J., \& Magley, V. J. (1997). Antecedents and consequences of sexual harassment in organizations: A test of an integrated model. Journal of Applied Psychology, 82, 578-589.

Gross, J. J., \& John, O. P. (2003). Individual differences in two emotion regulation processes: Implications for affect, relationships, and well-being. Journal of Personality and Social Psychology, 85, 348-362.

Pryor, J. B. (1987). Sexual harassment proclivities in men. Sex Roles, 17, 269-290. 
Sackett, P. R. (2002). The structure of counterproductive work behaviors: Dimensionality and relationships with facets of job performance. International Journal of Selection and Assessment, 10, 5-11.

Tomassetti, A., J., Dalal, R. S., \& Kaplan, S. (2016). Is policy capturing really more resistant than traditional self-report techniques to socially desirable responding? Organizational Research Methods, 19, 255-285.

Venkataramani, V., \& Dalal, R. S. (2007). Who helps and harms whom? Relational antecedents of interpersonal helping and harming in organizations. Journal of Applied Psychology, 92, 952-966.

Winter, D. G., John, O. P., Stewart, A. J., Klohnen, E. C., \& Duncan, L. E. (1998). Traits and motives: Toward an integration of two traditions in personality research. Psychological Review, 105, 230-250. 